\title{
High-Speed Cutting of Synthetic Trabecular Bone- A Combined Experimental-Computational Investigation
}

\author{
Macdarragh $\mathrm{O}^{\prime}$ Neill $^{1}$ and Ted J. Vaughan ${ }^{1, *}$ \\ 1 Biomedical Engineering and Biomechanics Research Centre, School of Engineering, College of Science and \\ Engineering, National University of Ireland Galway, Galway, Ireland. \\ * Correspondence: Dr. Ted Vaughan ted.vaughan@nuigalway.ie
}

Copyright: (c) 2021 by the authors. Submitted for possible open access publication under the terms and conditions of the Creative Commons Attribution (CC BY) license (https://creativecommons.org/license s/by/4.0/).

\begin{abstract}
Orthopaedic surgical cutting instruments are required to generate sufficient forces to penetrate bone tissue, while minimizing the risk of thermal and mechanical damage to the surrounding environment. This study presents a combined experimental-computational approach to determine relationships between key cutting parameters and overall cutting performance of a polyurethanebased synthetic trabecular bone analogue under orthogonal cutting conditions. An experimental model of orthogonal cutting was developed, whereby an adaptable cutting tool fixture driven by a servo-hydraulic uniaxial test machine was used to carry out cutting tests on Sawbone ${ }^{\circledR}$ trabecular bone analogues. A computational model of the orthogonal cutting process was developed using Abaqus/Explicit, whereby an Isotropic Hardening Crushable Foam elastic-plastic model was used to capture the complex post-yield behaviour of the synthetic trabecular bone. It was found that lower tool rake-angles resulted in the formation of larger discontinuous chips and higher cutting forces, while higher rake angles tended to lead to more continuous chip formation and lower cutting forces. The computational modelling framework provided excellent predictions of both chip formation and axial cutting forces over the wide range of cutting parameters, when compared to experimental observations. This represents the first experimentally-validated computational modelling framework for orthogonal cutting of trabecular bone and excellent potential to be applied to more complex three-dimensional cutting processes in the future.
\end{abstract}

Keywords: Surgical Cutting 1; Trabecular Bone 2; Finite Element Analysis 3 Cellular Solids 4

\section{Introduction}

Bone is a naturally occurring composite material whose constituent phases are hierarchically organised to provide a highly optimised structure that exhibits high stiffness and excellent resistance to fracture, while also being lightweight for efficient movement. The complex structural arrangement of bone gives rise to anisotropic, rate-dependent failure behaviour, which varies significantly depending on tissue composition and architecture [1-3]. This presents significant challenges in the development of surgical cutting instruments, which are required to generate sufficient forces to penetrate bone tissue while minimizing the risk of thermo-mechanical damage to the surrounding tissue. The biomechanics of cutting processes is further complicated by the range of complex interactions taking place at the tool-bone interface, particularly when three-dimensional cutting processes such as sawing (James et al., 2014), drilling [4] and burring [5] are considered. Both experimental and computational models of two-dimensional orthogonal cutting are widely used as a platform to investigate the influence of key cutting parameters, such as tool geometry, cutting depth and/or feed-rate, on overall cutting performance [6-10]. However, the vast majority of these studies have focussed on cutting process in cortical 
bone, and to date, there is a distinct lack of studies examining the biomechanics of cutting in trabecular bone [11].

Trabecular bone is a highly porous cellular structure composed of a complex microarchitecture, with its mechanical properties depending on numerous factors including age, sex, species and anatomic site [12-14]. Due to the inherent variability in trabecular bone mechanics, many experimental studies exploit commercially-available trabecular bone analogue materials for biomechanical testing of cutting and drilling operations [15, 16]. The most widely used synthetic substitute for trabecular bone comprises of "cellularrigid" and "solid-rigid" polyurethane (PU) foams that have been designed to replicate the cellular structure and mechanical properties as the tissue itself. Malak \& Anderson [8] used these PU foams of varying density and cell-size (Sawbones, Pacific Research Labs, Malmö, Sweden) to carry out a detailed experimental investigation of the role of cutting parameters on overall cutting performance under orthogonal cutting conditions. Key features were identified, in particular that smaller tool rake angles and larger cutting depths producing larger cutting forces and more discontinuous chip formation, while higher rake angles at lower cutting depths tended towards more continuous chip formation. It was later demonstrated that many similar trends were observed when bovine trabecular bone was considered [9]. While these experimental studies have identified key functional properties of tool performance and resulting chip formation, they fail to provide a detailed understanding of tool-bone interactions and features governing failure processes ahead of the tool tip, which has given rise to computational approaches for orthogonal cutting.

To date, the vast majority of computational modelling frameworks for orthogonal cutting have been developed for metal machining applications, where robust predictions of chip formation, cutting forces and heat generation have been possible [17-19]. These modelling frameworks benefit from relatively homogeneous material behaviour and several well-established plasticity formulations available that are available to describe postyield behaviour of metallic materials $[17,19,20]$. By far, the most widely used plasticity formulation in cutting simulations is the Johnson-Cook model, which is a strain-rate and temperature-dependent version of Von Mises plasticity [21]. Although this model was developed for metals, many computational models of cutting processes in both cortical [22] and trabecular bone [23] have implemented the Johnson-Cook model in an attempt to capture post-yield behaviour, despite the complex material behaviour associated with both tissue types. To date, few studies (if any) have compared their predictions to experiments to determine the suitability of the Johnson-Cook model in predicting cutting processes in orthopaedic applications [24-26]. In particular, it has been demonstrated that both Drucker-Prager and Crushable Foam plasticity formulations are more effective than Von-Mises formulations in capturing post-yield behaviour of both trabecular bone and synthetic bone analogues, [27, 28], as they account for pressure-dependant yield hardening observed in these cellular solids. However, both the implementation and suitability of pressure-sensitive plasticity formulations in predicting cutting processes in cellular solid materials has not been explored in detail.

This study presents, for the first time, an experimentally-validated computational modelling framework for two-dimensional orthogonal cutting of a synthetic trabecular bone analogue material (Sawbones, Pacific Research Labs, Malmö, Sweden). An experimental model of high-speed orthogonal cutting is developed, whereby an adaptable cutting tool fixture driven by a servo-hydraulic uniaxial test machine characterises cutting performance for range of conditions. In parallel, a computational modelling framework for orthogonal cutting is presented, with the suitability of both Johnson-Cook and Isotropic Crushable Foam plasticity formulations evaluated. Using this combined experimental-computational approach, a systematic evaluation of the effects of various cutting parameters, such as rake angle and cutting depth, on cutting performance is presented.

\section{Materials and Methods}




\subsubsection{Dynamic uniaxial compression experiments}

Uniaxial compression tests were performed using the hydraulic Dartec Series HC10 uniaxial test machine to evaluate the rate-dependent properties of the PU foam. Ten millimetre cubic specimens of Sawbone ${ }^{\circledR}$ grade $20\left(\rho=0.32 \mathrm{~g} / \mathrm{cm}^{3}\right)$ solid rigid-closed cell PU foam (Pacific Research Labs, Malmö, Sweden) were tested at three different uniaxial strain rates $\dot{\varepsilon}=0.1 \mathrm{~s}^{-1}, 1 \mathrm{~s}^{-1}, 10 \mathrm{~s}^{-1}$ to a nominal strain of $\varepsilon=0.6$ at room temperature $(\mathrm{n}=3$. Force-displacement data was recorded by the machine load cell and crosshead, from which nominal stress-nominal strain curves were constructed based on undeformed specimen dimensions. The apparent compressive Young's modulus $(E)$ was computed as the slope of the initial linear-elastic region. The yield stress $\left(\sigma_{\mathrm{y}}\right)$ was determined through the $0.2 \%$ offset method. The results of these tests formed the basis of constitutive model parameters used in the computational model, with results summarised in Figure 4 and Table 5.

2.1.2 High-speed orthogonal cutting experiments

An experimental model of high-speed orthogonal cutting process was developed to evaluate cutting forces generated during high-speed orthogonal cutting of the PU foam analogue, which consisted of custom-built cutting tool and hydraulic Dartec Series HC10 uniaxial testing machine (see Figure 1). The cutting tool was attached to the upper crosshead of the Dartec machine, with the PU foam samples fixed beneath using custom-built clamps. Using a removable pin, the cutting tool rake angle $(\alpha)$ was varied to test $\alpha=$ $0^{\circ}, 20^{\circ}, 45^{\circ}$ and $60^{\circ}$, with corresponding clearance angles of $55^{\circ}, 35^{\circ}, 10^{\circ}$ and $5^{\circ}$, respectively. The PU foam was machined to rectangular specimens of $30 \mathrm{~mm}$ length, $40 \mathrm{~mm}$ height and $7.5 \mathrm{~mm}$ width. A total of 24 high-speed cutting tests were performed on the material, using a constant cutting velocity of $v=200 \mathrm{~mm} / \mathrm{s}$, with two separate cutting depths of $h=1 \mathrm{~mm}$ and $h=2 \mathrm{~mm}$ tested. Force-displacement data was recorded, with results from axial cutting force (parallel to direction of cutting) normalised and presented as the cutting force per unit (mm) thickness of material. A high-speed camera (Sony DSCRX100 III) was used to visualise deformation and chip formation during the cutting experiments, with images captured at 250 frames per second.

(a)

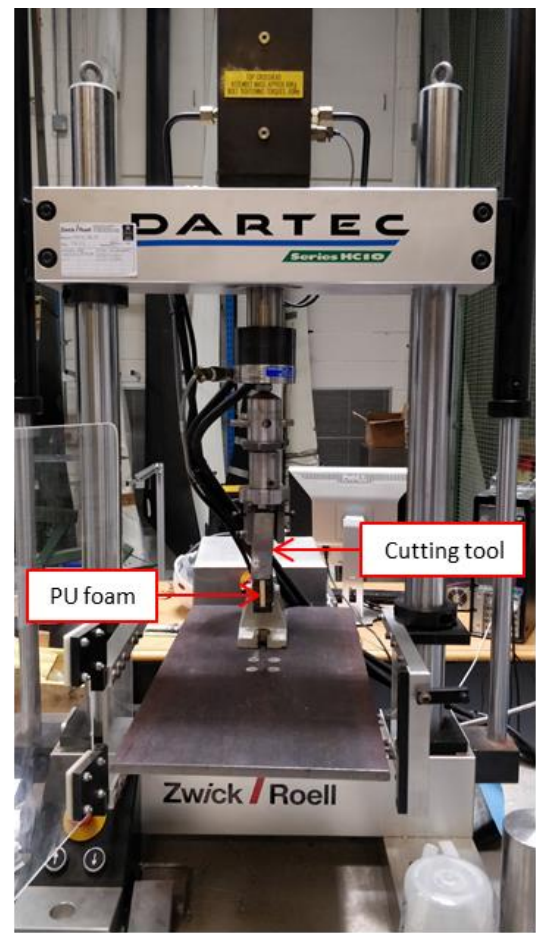

(b)

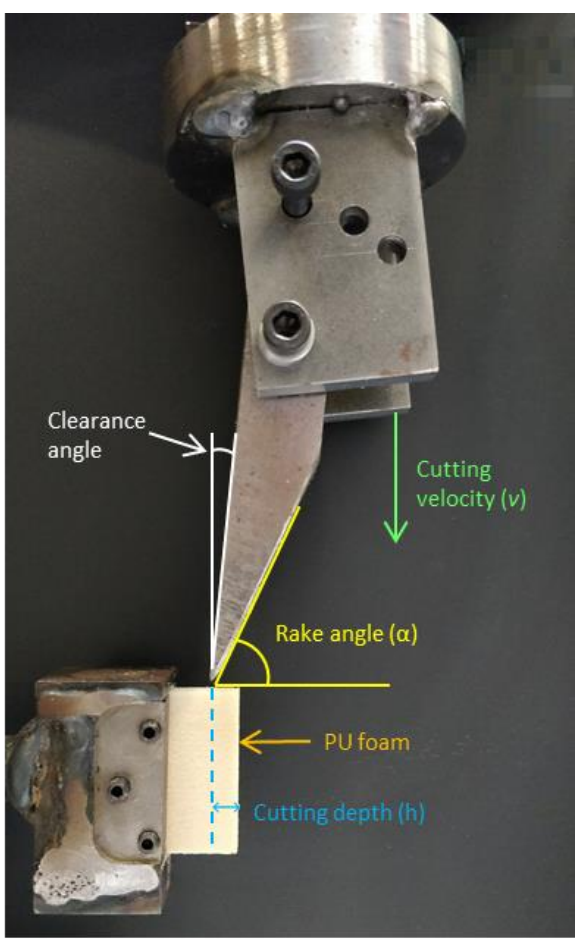


Figure 1. (a) Dartec Series HC10 uniaxial testing machine with custom-built orthogonal cutting rig (b) high-speed orthogonal test setup illustrating adjustable rake angle and key cutting parameters.

100 101 102 103 104 105 106 107 108 109 110 111 112 113 114 115 116 117 118 119 120 121 122 123 terial.

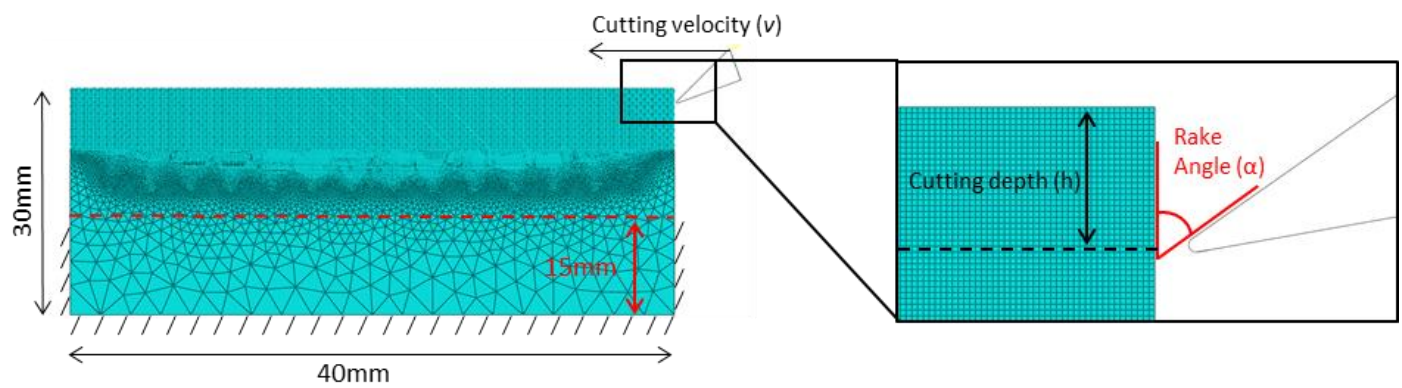

Figure 2: Finite element model dimensions, boundary conditions and discretisation of the PU workpiece. C3D8R in the tool-material contact region, C3D6 outside this region. Also illustrated is rake angle and cutting depth.

\subsubsection{Material constitutive model implementation}

To capture the behaviour of the workpiece during the cutting process, two plasticity formulations are implemented: (i) Johnson-Cook plasticity, which has been widely-used but does not account for pressure-dependent yielding and (ii) Isotropic Crushable Foam (CFI) plasticity, which does include a pressure-dependent yield criterion. A damage evolution law was also implemented in conjunction with both plasticity models to account for post-yield softening/failure behaviour.

(i) Johnson-Cook plasticity: The isothermal strain-rate dependent Johnson-Cook plasticity model has the following form and is essentially a strain-rate dependent version of the Von Mises yield function, given by,

$$
\sigma=\left[A+B \varepsilon_{\text {eff }}^{p}{ }^{n}\right][1+C \ln \dot{e}]
$$


Where $\sigma$ is the material flow stress, $\varepsilon_{e f f}^{p}$ is the effective plastic strain and $\dot{\varepsilon}=\frac{\varepsilon_{e f f}^{p}}{\dot{\varepsilon}_{0}}$, where $\dot{\varepsilon}_{0}$ is the reference strain rate used to determine the model constants $A, B \mathcal{E} n$. The first bracketed term accounts for strain-hardening effects, while the second bracketed term accounts for strain-rate dependency. Model constants for the PU20 were determined from the results from uniaxial compression tests, described in Section 2.1, and are provided in Table 1.

Table 1. Johnson-Cook plasticity model material parameters for PU20

\begin{tabular}{ccccc}
\hline $\mathbf{A}$ & $\mathbf{B}$ & $\mathbf{n}$ & $\mathbf{C}$ & $\dot{\boldsymbol{e}}_{\mathbf{0}}$ \\
\hline $5 \mathrm{MPa}$ & $7.5 \mathrm{MPa}$ & 0.55 & 0.04 & 0.1 \\
\hline
\end{tabular}

(ii) Crushable Foam with Isotropic Hardening (CFI) Plasticity Model: The CFI plasticity model is based on a model by Deshpande and Fleck (2000) and has been widelyused to represent the post-yield behaviour of cellular materials. The CFI model phenomenologically represents the buckling of cell walls under compression and has a pressuredependent yield criterion, which is given by

$$
\begin{gathered}
F=\sqrt{q^{2}+\alpha^{2} p^{2}}-B=0 \\
\text { where } \quad B=\alpha p_{c} \\
\text { and } \quad \alpha=\frac{3 K}{\sqrt{9-K^{2}}} \\
\text { and } K=\frac{\sigma_{c}^{0}}{p_{c}^{0}}
\end{gathered}
$$

The flow potential for the CFI model is given by

$$
\begin{aligned}
& G=\sqrt{q^{2}+\beta^{2} p^{2}} \\
& \beta=\frac{3}{\sqrt{2}} \sqrt{\frac{1-2 v_{p}}{1+v_{p}}}
\end{aligned}
$$

In the above equations, $\alpha$ is the shape of the yield ellipse in the Von Mises-Pressure stress plane, $B$ is the size of the yield ellipse, $p_{c}$ is the yield strength in hydrostatic compression, $\mathrm{q}$ is the Von Mises yield stress, $K$ is the compression yield stress ratio, $\sigma_{c}^{0}$ is the initial yield strength in uniaxial compression, $p_{c}^{0}$ is the initial yield strength in hydrostatic compression, $\beta$ is the ellipse for the potential flow and $v_{p}$ is the plastic Poisson's ratio. The yield ellipse progression is governed by the equivalent plastic strain [30]. Values for the compression yield stress ratio and the plastic Poisson's ratio and are summarised in Table 2, which were obtained from the results of Kelly and McGarry [27] who also tested PU20. The isotropic hardening data was obtained on experimental uniaxial compression data and is prescribed in the model as a piecewise-linear curve. The strain-rate dependence of the yield surface is also input in tabular form in the Abaqus software as part of the material property definition, which defines a Yield Stress ratio in terms of equivalent plastic strain rate, which is determined from the uniaxial compressive behaviour of the PU20 (described in Section 2.1). 
Table 2. Isotropic crushable foam plasticity model material parameters for PU20.

\begin{tabular}{ccc}
\hline & $\begin{array}{c}\text { Compression Yield Stress Ratio } \\
(\mathrm{K})\end{array}$ & $\begin{array}{c}\text { Plastic Poisson's Ratio }\left(\boldsymbol{v}_{p}\right) \\
\text { Crushable foam }\end{array}$ \\
Model constants & 0.7 & 0.23 \\
\hline & Yield Stress $(\mathrm{MPa})$ & Uniaxial Plastic Strain \\
\hline & 3.7 & 0 \\
Crushable Foam & 5.2 & 0.01 \\
Piecewise Hard- & 6.5 & 0.02 \\
ening Data & 7.1 & 0.04 \\
& 7.2 & 0.06 \\
& 7.47 & 0.08 \\
& 7.56 & 0.1 \\
\hline
\end{tabular}

Damage evolution law: Both the Johnson-Cook and CFI plasticity models were coupled to a damage evolution law (often termed the Johnson-Cook damage model) to describe softening behaviour of the material post-yield. This is described by three failure parameters $\left(\mathrm{d}_{1}, \mathrm{~d}_{2}\right.$ and $\left.\mathrm{d}_{3}\right)$, represented by the following equation

$$
\bar{\varepsilon}_{f}=\left[d_{1}+d_{2} \exp \left(d_{3} \eta\right)\right]
$$

Where $\bar{\varepsilon}_{f}$ is the equivalent strain-at-failure and $\eta$ is the stress triaxiality parameter which is given as the ratio of Hydrostatic stress to Von Mises equivalent stress. This damage evolution law was calibrated through an iterative process whereby the damage parameters $\left(d_{1}-d_{3}\right)$ and the effective plastic displacement at failure parameter $\left(\bar{u}_{f}^{p l}\right)$ were adjusted until the predicted chip formation provided good agreement with those observed in the experiments (Table 3$)$. The damage parameters $\left(d_{1}-d_{3}\right)$ and the effective plastic displacement at failure parameter $\left(\bar{u}_{f}^{p l}\right)$ used for these simulations are provided in Table 3. The damage evolution law defines the element removal process. Damage is initiated once the threshold for equivalent strain-at-failure is exceeded. Beyond this point, a reduction in stiffness and strength occurs until the defined equivalent plastic strain at failure is reached, at this point the element is deleted from the mesh.

Table 3. Calibrated damage evolution law parameters for PU20.

\begin{tabular}{cccc}
\hline $\boldsymbol{d}_{1}$ & $\boldsymbol{d}_{2}$ & $\boldsymbol{d}_{3}$ & $\overline{\boldsymbol{u}}_{\boldsymbol{f}}^{\boldsymbol{p l}}(\boldsymbol{m})$ \\
\hline-0.77 & 2.5 & -1.75 & $2 \mathrm{E}-05$ \\
\hline
\end{tabular}

2.2.3 High-speed orthogonal cutting simulations

Cutting simulations were performed using a dynamic, explicit step with automatic incrementation in the Abaqus Explicit finite element code. For all simulations, the cutting tool was prescribed a velocity of $v=200 \mathrm{~mm} / \mathrm{s}$. A variation of cutting parameters was carried out using this modelling framework, with rake angles of $\alpha=0^{\circ}, 20^{\circ}, 45^{\circ}$ or $60^{\circ}$ and cutting depths of $h=1 \mathrm{~mm}$ and $h=2 \mathrm{~mm}$ simulated.

\subsection{Categorisation of chip formation}

This study categorises chip formation observed in cutting experiments according to categories established by Malak and Anderson [8], in their experimental study on orthogonal cutting of PU foams. Type 1, 2 and 3 chip formation categories are described in Table 
4 and illustrated schematically in Figure 3, along with typical resulting cutting force-tool displacement curves that correspond to each type of chip formation. A new type of chip formation was observed in this current study, which has not been previously reported and this has been defined as "Type 4" chip formation and is also described in Table 4.

Table 4. Categorisation of chip formation based on study by Malak and Anderson (2005)

\begin{tabular}{cc}
\hline Chip Type & Chip Type \\
\hline $\begin{array}{c}\text { Surface fragmentation } \\
\text { (Type 1) }\end{array}$ & $\begin{array}{c}\text { An accumulation of broken cell walls, formed as the tool scrapes along } \\
\text { the surface at low cut depths relative to cell size (not observed in this } \\
\text { study, so not shown in Figure 3). }\end{array}$ \\
$\begin{array}{c}\text { Continuous chip formation } \\
\text { (Type 2) }\end{array}$ & $\begin{array}{c}\text { A continuous plastic deformation of the material without fracture ahead } \\
\text { of the cutting edge and results in the smooth flow of the chip up the rake } \\
\text { face. }\end{array}$ \\
\hline $\begin{array}{c}\text { Discontinuous chip for- } \\
\text { mation (Type 3) }\end{array}$ & $\begin{array}{c}\text { Fragmented chips forming and may be further subdivided into (i) con- } \\
\text { fined crack propagation and lifting of the chip (Type 3a), (ii) continuous } \\
\text { crack propagation (Type 3b) and (iii) shearing (Type 3c). }\end{array}$ \\
\hline $\begin{array}{c}\text { Obliteration (Type 4) } \\
\text { Material ahead of the tool is obliterated resulting in a fine dust. Type 4 } \\
\text { chips form a compression failure in the material, ahead of a relatively low } \\
\text { rake angle, approaching } 0^{\circ} \text {. This forms an acceptable chip type in the } \\
\text { form of a fine dust and is a result of the brittle failure of the cell walls } \\
\text { within the cellular material. }\end{array}$ \\
\hline
\end{tabular}
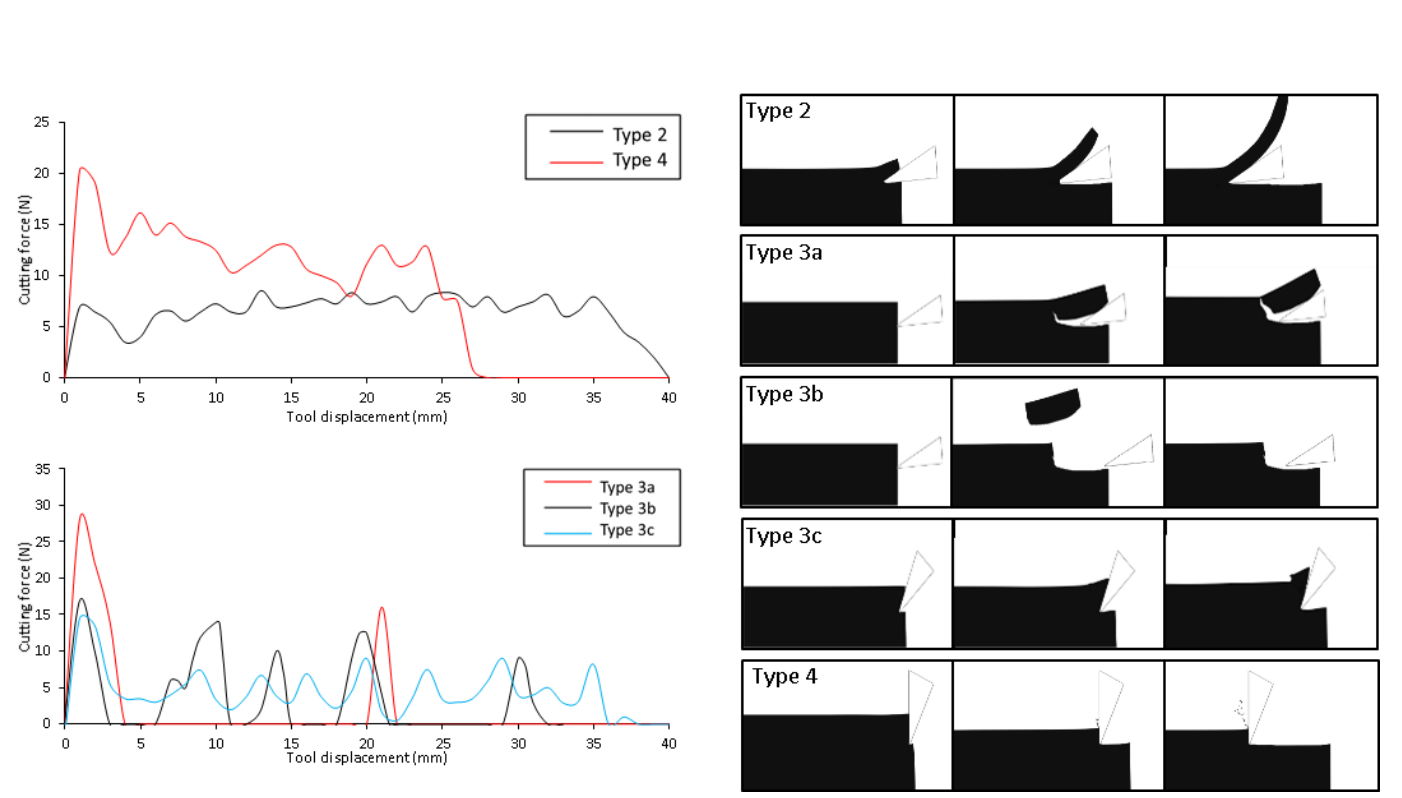

Figure 3: Schematic drawing of the types of chip formation are presented alongside the typical cutting force-tool displacement curves that correspond to each type of chip formation. 


\subsection{Uniaxial dynamic compression tests}

Experimentally measured nominal stress-nominal strain curves for the dynamic uniaxial compression testing of PU20 are shown in Figure 4, with associated Young's Modulus and Yield Stress (mean \pm SD (range)) shown in Table 5. The measured values for Young's Modulus are $E=155 \pm 2.6 \mathrm{MPa}$ and $E=197.9 \pm 28.6 \mathrm{MPa}$ at strain rates of $\dot{\varepsilon}=0.1 \mathrm{~s}^{-1}$ and $\dot{\varepsilon}=10 \mathrm{~s}^{-1}$, respectively. The yield stress for PU20 was found to be $\sigma_{y}=$ $5.7 \pm 0.1 \mathrm{MPa}$ are $\sigma_{y}=6.9 \pm 0.3 \mathrm{MPa}$ at strain rates of $\dot{\varepsilon}=0.1 \mathrm{~s}^{-1}$ and $\dot{\varepsilon}=10 \mathrm{~s}^{-1}$, respectively.

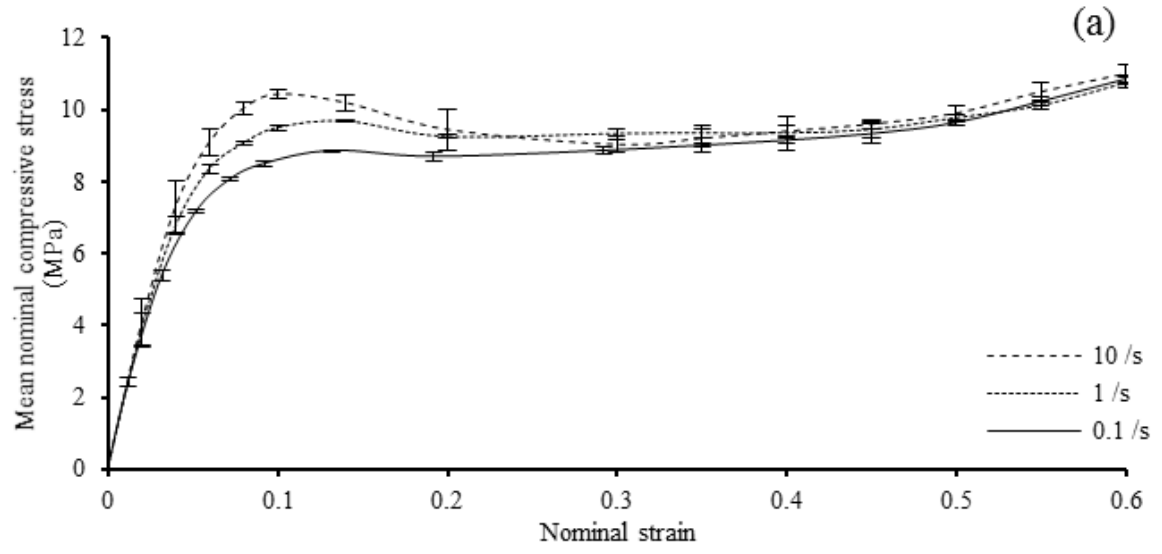

Figure 4: Nominal stress-nominal strain curves for PU20 obtained from dynamic uniaxial compression testing at high strain rates.

Table 5. Experimentally measured material properties for PU20 under uniaxial compression at two strain rates $\left(0.1 \mathrm{~s}^{-1}\right.$ and $\left.10 \mathrm{~s}^{-1}\right)$. Results are reported as mean \pm SD (range). Johnson-Cook plasticity model material parameters for PU20

\begin{tabular}{ccccc}
\hline & \multicolumn{2}{c}{ Young's modulus, $E \mathbf{~ ( M P a )}$} & \multicolumn{2}{c}{ Yie!d stress (MPa) } \\
\hline Strain-rate & $0.1 \mathrm{~s}^{-1}$ & $10 \mathrm{~s}^{-1}$ & $0.1 \mathrm{~s}^{-1}$ & $10 \mathrm{~s}^{-1}$ \\
\hline & $155.1 \pm 2.6$ & $197.9 \pm 28.6$ & $5.7 \pm 0.1$ & $6.9 \pm 0.3$ \\
\hline
\end{tabular}

\subsection{High-speed orthogonal cutting tests}

\subsubsection{Chip formation}

Following the analysis of the results from both the Johnson-Cook and CFI plasticity models, it was found that the CFI model was more accurate in predicting the experimental cutting forces (see section 3.2.2) and better captured the chip formation. Therefore, Figure 5 compares experimental and computational (CFI model only) chip formation at two time points during the cutting process for all cutting parameters considered (i.e. rake angle and cutting depth). The computational model accurately predicts the formation and separation of chips when compared to the experimental observations. In general, it was found that high rake angles and low cutting depths tends towards more continuous (Type 2) chip formation, while decreasing the rake angle and/or increasing the cutting depth led to the formation of more discontinuous chip types (Type 4, 3a, 3b, 3c).

Figure 5a shows that for a $\alpha=0^{\circ}$ and $h=2 \mathrm{~mm}$, steady-state chip type was observed, with obliteration of the material (Type 4) and some discontinuous fragments occurring. Interestingly, a large crack developed in the sample towards the end of the test as the tool exited the workpiece, a feature that was also predicted in the computational model following its prediction of steady-state chip formation. Figure $5 b$ shows that for a 
$\alpha=0^{\circ}$ and $h=1 \mathrm{~mm}$, material obliteration (Type 4) and discontinuous fragmentation occurred experimentally, with the computational model predicting both of those features.

Figure 5c illustrates that for a $\alpha=20^{\circ}$ and $h=2 \mathrm{~mm}$, one discontinuous (Type 3b) chip formed followed by a large crack which split the sample ahead of the tool tip. The model captured the features of discontinuous (Type 3b) chipping and the edge effect quite well. However, discontinuous (Type 3c) also occurred computationally but not experimentally.

Figure $5 \mathrm{~d}$ presents the chip formation for $\alpha=20^{\circ}$ and $h=1 \mathrm{~mm}$. The initial steady-state chip type was discontinuous (Type $3 a / 3 b$ ), suggesting that these cutting parameters may be within a transition zone between the two chip types. Similar to the previous case, as the tool exited the workpiece a large crack occurred ahead of the tool tip. For this case, the model incorrectly predicted discontinuous (Type 3c) but predicted similar cracking of the material due to the edge effect. Of the 8 simulations, this was the only case where the model failed to accurately predict the steady-state chip type.

Figure 5e presents the chip formation for $\alpha=45^{\circ}$ and $h=2 \mathrm{~mm}$, where discontinuous chip formation with confined crack propagation and lifting of the chips (Type 3a) occurred experimentally, and also captured by the computational model. Figure $5 \mathrm{f}$ presents the results for $\alpha=45^{\circ}$ and $h=1 \mathrm{~mm}$. Similarly, to Fig 5e discontinuous chip formation with confined crack propagation occurred (Type 3a) was observed. However, in this case, the size of the chips formed were smaller due to the lower cutting depth. Again, these features were captured by the computational model.

Figures $5 \mathrm{~g}$ and $5 \mathrm{~h}$ present the chip formation for $\alpha=60^{\circ}$ at $h=2 \mathrm{~mm}$ and $h=$ $1 \mathrm{~mm}$, respectively. In both cases, discontinuous chip formation with confined crack propagation and lifting of the chips (Type 3a), was observed. Again, for lower cutting depths, smaller chips were produced, with all these features being captured by the computational model. A summary of all chip types observed experimentally and those predicted by the computational model is provided in Table 6.

Table 6. Predominant steady-state chip types that occurred for each of the cutting parameters for the high-speed orthogonal cutting of PU20. *Note: Experimental (CFI model)..

\begin{tabular}{ccccc}
\hline & $\mathbf{0}^{\circ}$ & $\mathbf{2 0}^{\circ}$ & $\mathbf{4 5}^{\circ}$ & $\mathbf{6 0}^{\circ}$ \\
\hline $\begin{array}{c}\text { 2mm Cutting } \\
\text { Depth }\end{array}$ & Type 4 (Type 4) & $\begin{array}{c}\text { Type 3b (Type } \\
3 b / 3 c)\end{array}$ & Type 3a (Type 3a) & Type 3a (Type 3a) \\
\hline $\begin{array}{c}\text { 1mm Cutting } \\
\text { Depth }\end{array}$ & Type 4 (Type 4) & $\begin{array}{c}\text { Type 3a/3b (Type } \\
3 c)\end{array}$ & Type 3a (Type 3a) & Type 3a (Type 3a) \\
\hline
\end{tabular}


(a)

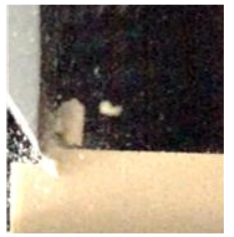

(b)

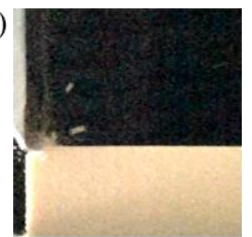

(c)

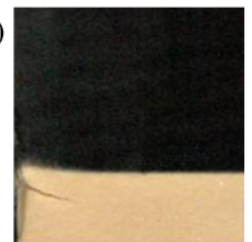

(d)

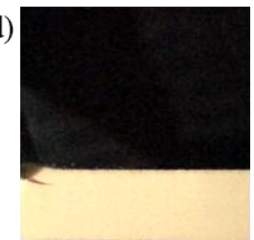

(e)

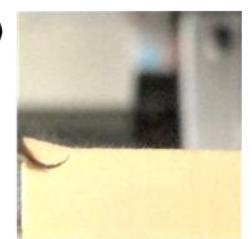

(f)

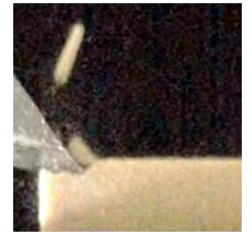

(g)

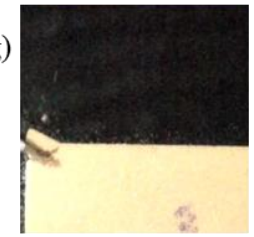

(h)

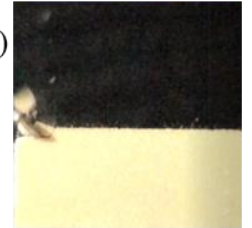

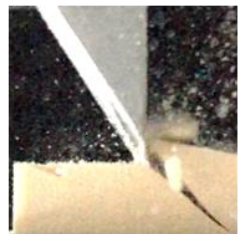
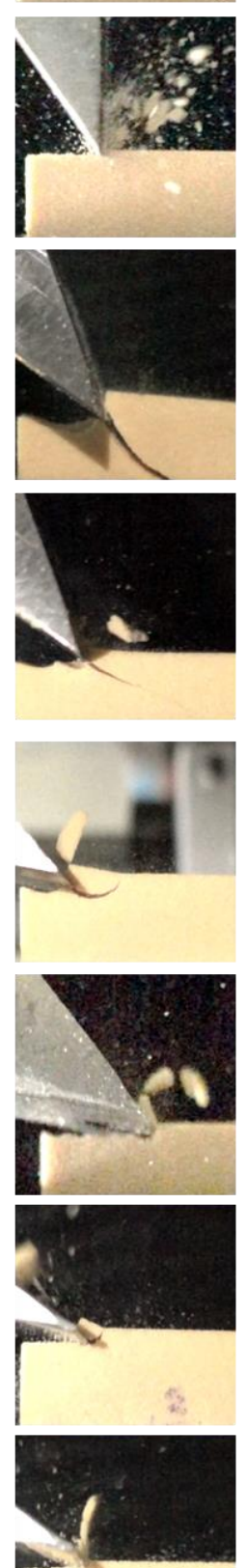
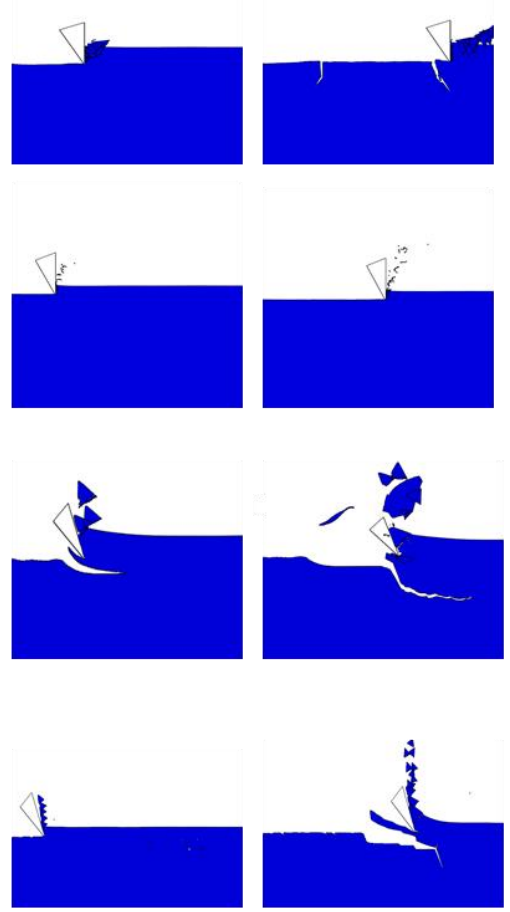

Cut depth: $1 \mathrm{~mm}$ Rake angle: $20^{\circ}$
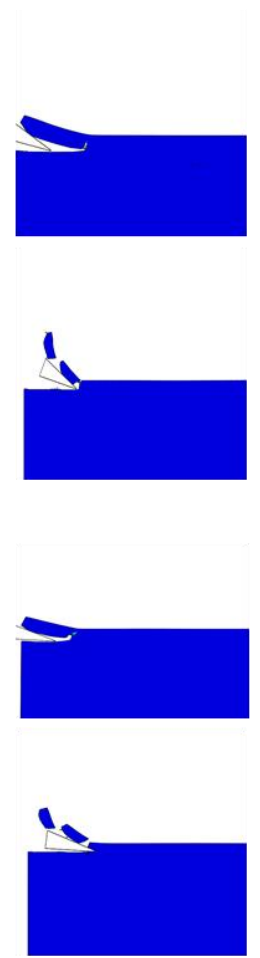

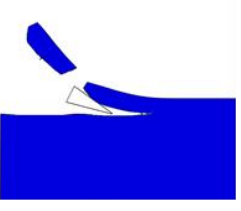

Cut depth: $2 \mathrm{~mm}$ Rake angle: $45^{\circ}$

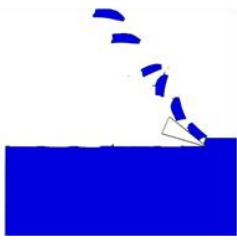

Cut depth: $1 \mathrm{~mm}$ Rake angle: $45^{\circ}$
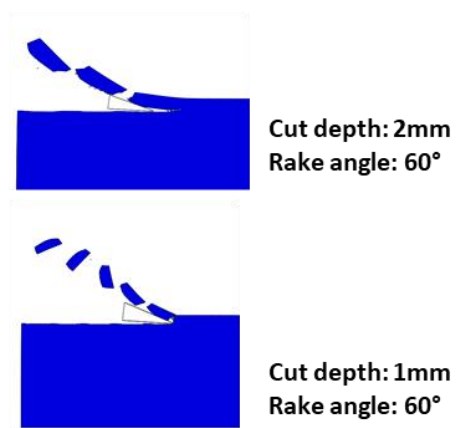

Cut depth: $2 \mathrm{~mm}$ Rake angle: $0^{\circ}$

ut depth: $1 \mathrm{~mm}$ Rake angle: $0^{\circ}$

Cut depth: $2 \mathrm{~mm}$ Rake angle: $20^{\circ}$

Figure 5: Visual comparison between experimental and computational (CFI model) analysis at two time points for the high-speed orthogonal cutting of PU20 for a range of cutting parameters. (a) $\alpha=0^{\circ}, h=2 \mathrm{~mm}$; (b) $\alpha=0^{\circ}, h=1 \mathrm{~mm}$; (c) $\alpha=$

$20^{\circ}, h=2 \mathrm{~mm}$; (d) $\alpha=20^{\circ}, h=1 \mathrm{~mm}$; (e) $\alpha=45^{\circ}, h=2 \mathrm{~mm}$; (f) $\alpha=45^{\circ}, h=1 \mathrm{~mm}$; (g) $\alpha=60^{\circ}, h=2 \mathrm{~mm} ;$ (h) $\alpha=60^{\circ}, h=1 \mathrm{~mm}$. 


\subsubsection{Cutting force}

The cutting force-tool displacement data measured from experimental tests (mean \pm $\mathrm{SD}, \mathrm{n}=3$ ) and predicted by computational models is presented in Figure 6 . The largest experimental cutting forces were measured at $\alpha=0^{\circ}$ and $h=2 \mathrm{~mm}$, while the smallest were measured at $\alpha=60^{\circ}$ and $h=1 \mathrm{~mm}$.

Figure 6a shows cutting force-displacement data for $\alpha=0^{\circ}$ and $h=2 \mathrm{~mm}$. The experimental curve shows an initial peak in cutting force followed by a large drop-off to zero which is a result of the propagation of a large crack within the sample, which was visible in chip formation analysis in Figure 5a. The computational CFI model predicts a similar cutting force to the experimental, with slight oscillations in the curve, with local maxima and minima caused by chip fragmentation. The crack that developed computationally (Fig 5a) did not cause complete separation of the sample, thus explaining why a large drop-off in the cutting force did not occur. While similar features are predicted by the J-C model, it overpredicts the cutting force compared to the measured experimental data for this case. Figure $6 \mathrm{~b}$ shows the cutting force-displacement data for $\alpha=0^{\circ}$ and $h=1 \mathrm{~mm}$. The experimental data resembles a typical material obliteration force curve as characterised in Section 2.3. A very good correlation is observed between the CFI model and experimental data, while the J-C model predicts higher cutting forces.

Figure $6 \mathrm{c}$ presents cutting force-displacement data for $\alpha=20^{\circ}$ and $h=2 \mathrm{~mm}$. The initial spike in cutting force is a result of the formation and separation of a large chip (Type $3 \mathrm{~b}$ ). The second spike in cutting force corresponds to a large crack propagating within the sample due to an edge effect. The CFI model predicted a combination of discontinuous (Type $3 b \& 3 c$ ) chip types (see Fig $5 c$ ). Thus, explaining the combination of cutting force-displacement curves (characterised in section 2.3) displayed in Fig 6c. The J$\mathrm{C}$ cutting force-displacement prediction has a similar profile to the CFI model but at a greater magnitude. Figure 6d shows cutting force-displacement results for $\alpha=20^{\circ}$ and $h=1 \mathrm{~mm}$. The experimental curve corresponds to discontinuous chip formation and is similar to that presented in Fig 6c. As previously mentioned (comments on Fig 5d), both computational models failed to accurately predict the experimental chip formation at these cutting parameters. This reflects the incorrect prediction of cutting force-displacement presented in Fig 6d.

Figure 6e shows the cutting force-displacement data for $\alpha=45^{\circ}$ and $h=2 \mathrm{~mm}$. This type of curve corresponds to discontinuous chip formation with confined crack propagation, as characterised in section 2.3. Discontinuous chip formation was found to fluctuate with a distinct wavelength, which was visually measured from the cutting forcedisplacement data. The wavelength is the distance between cutting force local maxima and corresponds to the length of the discontinuous chips formed. The cutting force local maxima and minima and curve wavelength are caused by confined crack propagation and lifting of the chips and is accurately predicted by the CFI model in this case (see Fig 5e). Figure $6 \mathrm{f}$ shows the cutting force-displacement data for $\alpha=45^{\circ}$ and $h=1 \mathrm{~mm}$. Similarly, to Fig 6e, this curve corresponds to discontinuous chip formation. The cutting force local maxima and curve wavelength are lower than in Fig 6e. The CFI model provides a good prediction of these results with the J-C model overestimating the cutting forces in both Fig 6e \& $6 f$.

Figure $6 \mathrm{~g}$ presents cutting force-displacement data for $\alpha=60^{\circ}$ and $h=2 \mathrm{~mm}$. The experimental data corresponds to discontinuous chip formation and is similar to Fig 6e \& 6f. However, this case presents non-zero cutting force local minima. The CFI model slightly underestimates the cutting forces local minima but still predicts cutting force local maxima and curve wavelength. Figure $6 \mathrm{~h}$ exhibits the cutting force-displacement data for $\alpha=60^{\circ}$ and $h=1 \mathrm{~mm}$. The experimental data could be misinterpreted as a corresponding curve to continuous chip formation. However, it in fact corresponds to discontinuous chip formation, with a relatively small wavelength. In this case, the CFI model predicts lower cutting forces than those measured experimentally and predicted by the J-C model. 

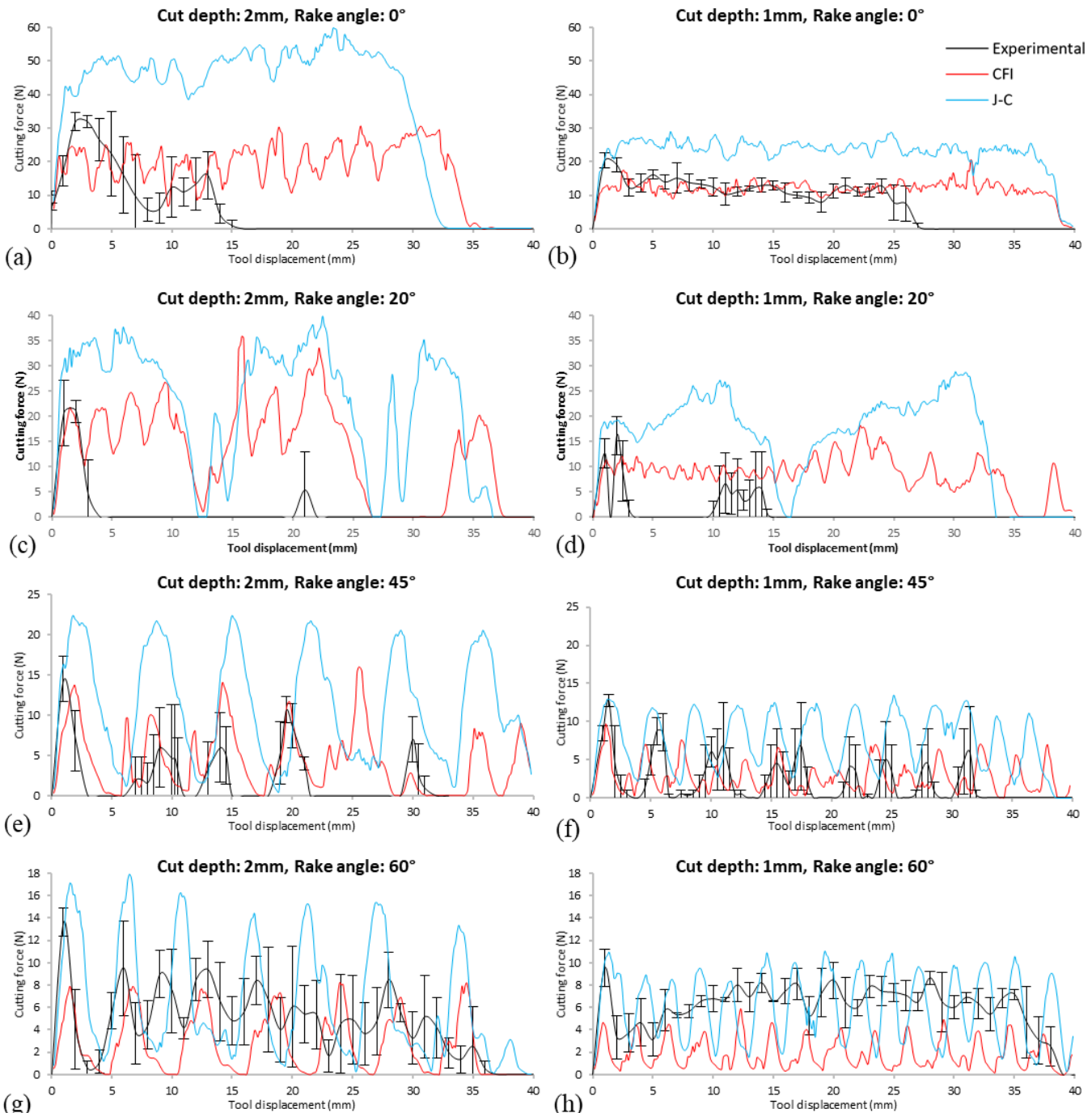

Figure 6: PU20 cutting force output (a) $\alpha=0^{\circ}, h=2 \mathrm{~mm}$; (b) $\alpha=0^{\circ}, h=1 \mathrm{~mm}$; (c) $\alpha=338$ $20^{\circ}, h=2 \mathrm{~mm} ;(\mathrm{d}) \alpha=20^{\circ}, h=1 \mathrm{~mm} ;(\mathrm{e}) \alpha=45^{\circ}, h=2 \mathrm{~mm} ;(\mathrm{f}) \alpha=45^{\circ}, h=1 \mathrm{~mm} ; \quad$ (g)

$$
\alpha=60^{\circ}, h=2 \mathrm{~mm} ; \quad \text { (h) } \alpha=60^{\circ}, h=1 \mathrm{~mm} \text {. }
$$

3.2.3 Wavelength of Discontinuous Chip Formation \& Specific cutting energies

Discontinuous chip formation was observed during many of the cutting parameters tested, with cutting force-displacement curves showing fluctuations of distinct wavelengths. The size of these wavelengths is directly related to the size of the chips formed. These fluctuations were quantified based on the experimentally measured cutting force data and Figure 7 shows the relationship between the wavelength of discontinuous chip formation and rake angle and cutting depth. Here, lower rake angles and larger cutting depths have higher measured wavelengths (larger chips were also observed in this case). No measurable wavelength was observed for a rake angle of $0^{\circ}$.

a) 

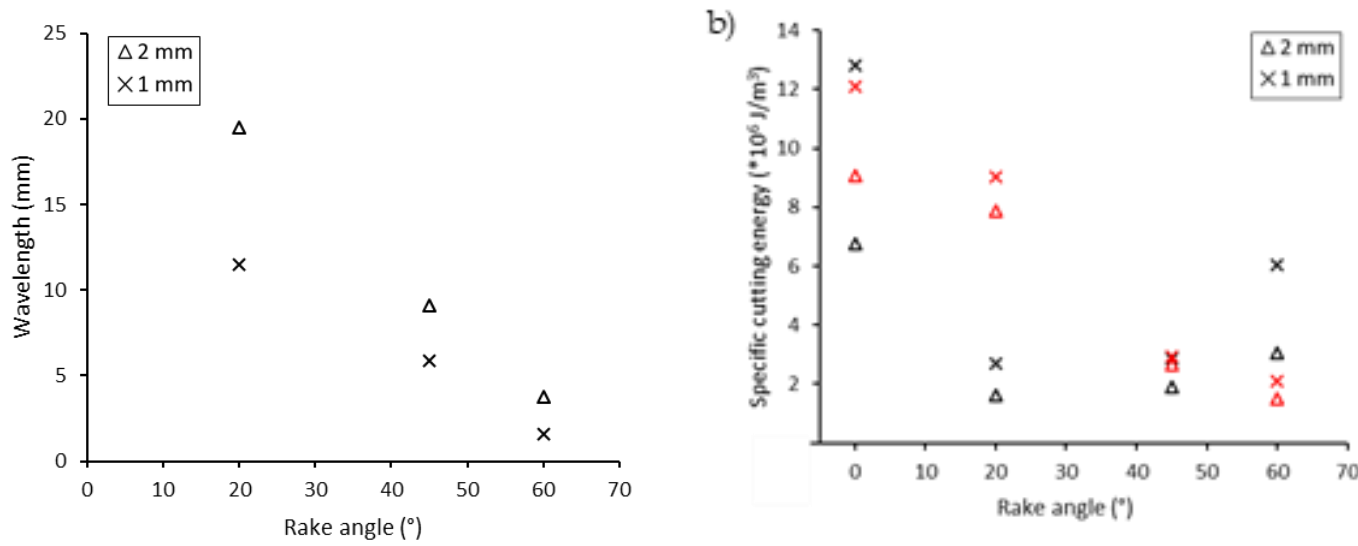

Figure 7: (a) Average wavelengths for discontinuous chip formation, determined from the experimental force curves in Figure 6. (b) Specific cutting energy as a function of rake angle (Black markers - experimental results, red markers - CFI model results)

The specific cutting energy $u$, which is the energy consumed per unit volume of material removed (Shaw, 2005), was calculated using

$$
u=\frac{F}{w h}
$$

where $F$ is the cutting force, $w$ is the width of the sample and $h$ represents the cutting depth. Figure 7(b) presents the relationship between specific cutting energy, rake angle and cutting depth. Increasing rake angle and increasing cutting depth correspond to a decrease in specific cutting energy. The CFI model predictions for specific cutting energies are superimposed in Figure 7(b) allowing comparison to the experimental results. The model provided a reasonable prediction of the experimental outcomes.

3.2.5 Tool-bone Interactions

Figure 8 shows contour plots of stress triaxiality $(\eta)$, which is defined as ratio of hydrostatic stress $(p)$ to Von Mises stress $(q)$, where $\eta=\frac{p}{q}$. Here, the contour limits are chosen as $\eta=-0.33$ and $\eta=0.33$, which represent values for unconfined compression and tension respectively. For these simulations, large regions of the workpiece tended to have values of stress triaxiality that were outside these limits $(-0.33<\eta<0.33)$, indicating that the hydrostatic pressure component ahead of the tool tip is substantial.

\begin{tabular}{|l|}
\hline TRIAX \\
(Avg: 75\%) \\
\begin{tabular}{l}
2.00 \\
0.33 \\
-0.33 \\
-2.00 \\
\hline
\end{tabular} \\
\hline
\end{tabular}

(a) Rake angle: $0^{\circ}$

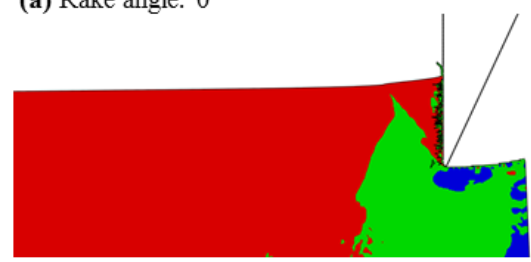

(c) Rake angle: $45^{\circ}$

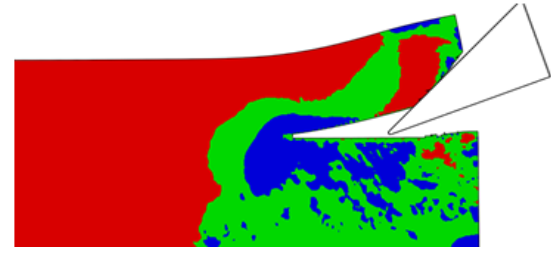

(b) Rake angle: $20^{\circ}$

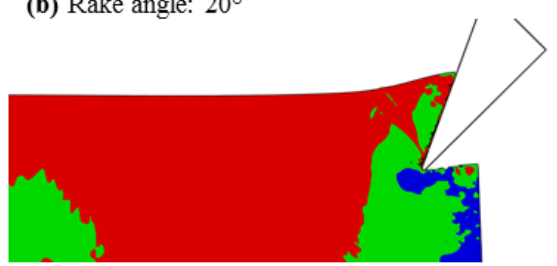

(d) Rake angle: $60^{\circ}$

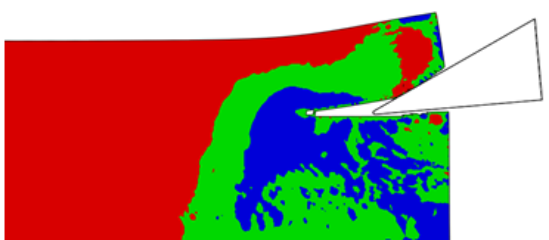

Figure 8: Contour plot illustrating the stress triaxiality involved in the high-speed orthogonal cutting of PU foams at a cutting depth of $h=2 \mathrm{~mm}$ and rake angles of (a) $\alpha=$ $0^{\circ}$; (b) $\alpha=20^{\circ}$; (c) $\alpha=45^{\circ}$; (d) $\alpha=60^{\circ}$. Green regions are stress triaxiality values within the limits of $-0.33<\eta<0.33$ and regions of blue and red are values of stress triaxiality above and below the limits, respectively. 


\section{Discussion}

A combined experimental-computational approach was used to determine important relationships between key cutting parameters and overall cutting performance of synthetic trabecular bone analogue under high-speed orthogonal cutting conditions. The study presents, for the first time, an advanced computational modelling framework for high-speed cutting of trabecular bone analogues, whose model parameters were determined experimentally. The modelling framework provided excellent predictions of both chip formation and axial cutting forces over the wide range of cutting parameters when compared to experimental measurements and observations, and has excellent potential to be used to examine more complex three-dimensional cutting processes in the future. Through the development of a novel experimental cutting rig, this study represents the first investigation of the high-speed $\left(v=200 \mathrm{~mm} \mathrm{~s}^{-1}\right)$ orthogonal cutting behaviour of PU foam. It was found that low rake angles $\left(\alpha=0^{\circ}\right)$ resulted in obliteration (Type 4$)$ of workpiece ahead of the tool tip and the highest cutting forces. Intermediate rake angles $\left(20^{\circ}<\right.$ $\alpha<45^{\circ}$ ) typically produced discontinuous chip formation, either through confined crack propagation and lifting of the chip (Type 3a), which was usually associated with smaller cutting depths, or continuous crack propagation ahead of the cutting tool (Type $3 \mathrm{~b}$ ) at larger cutting depths. Higher rake angles $\left(\alpha=60^{\circ}\right)$ resulted in the lowest cutting forces and tended towards more continuous chip formation (Type 2), providing a smoother finish on the cut surface. It is interesting that features of chip formation observed at each rake angle and cutting depth here are largely similar to the orthogonal cutting experiments carried out by Malak and Anderson [8], who tested a range of PU foams, however at much lower cutting speeds $\left(\mathrm{v}=0.187 \mathrm{~mm} \mathrm{~s}^{-1}\right)$, suggesting that the cutting rate does not have drastic effect on visual chip formation. Our study also identified a new mode of chip formation at a rake angle of $\alpha=0^{\circ}$, defined as Type 4 chip formation, which describes compression failure ahead of the tool tip resulting in the formation of a fine dust and some material fragmentation. This observed behaviour could be relevant for design of tools for burring operations, which tend to have very low (and sometimes negative) rake angles [16]. Our study also presents the efficiency of the cutting processes using the specific cutting energy $(u)$, a parameter defined as the energy consumed per unit volume of material removed [31]. With the emergence of minimally invasive surgical techniques [32], the requirement for more compact tools and surgical equipment with high cutting efficiency is becoming more important. The results from this study show that higher rake angles $\left(\alpha=20-60^{\circ}\right)$ generate lower specific cutting energies during the cutting process, a feature that could be exploited to optimise the design and efficiency of smaller surgical cutting tools.

This study also developed an advanced computational modelling framework for high-speed orthogonal cutting that provided excellent predictions of chip formation and cutting forces over the range of cutting parameters. This framework implements, for the first time, the strain rate- and pressure-dependent crushable foam yield criteria within the cutting model and directly compares its performance in capturing the experimental cutting process against the more widely-used Johnson-Cook model (originally developed for metals), with material constants for both plasticity formulations determined experimentally. It is interesting that the CFI model provided a more accurate prediction of cutting forces, while the Johnson-Cook plasticity model consistently overestimated the cutting forces (see Figure 6) in almost all cases. Previous studies have demonstrated that the yield behaviour of PU foams is pressure-dependent [27], or more specifically depends on the stress triaxiality $(\eta)$, which is defined as ratio of hydrostatic stress $(p)$ to Von Mises stress (q). Stress triaxiality values for unconfined compression and tension are $\eta=-0.33$ and $\eta$ $=0.33$, respectively. For more confined stress states, or if the stress triaxiality value moves outside of the limits $(-0.33<\eta<0.33)$, it would be expected that a Johnson-Cook plasticity model may fail to capture yielding behaviour. Figure 8 shows contour plots of stress triaxiality $\left(\eta=\frac{p}{q}\right)$ during the cutting process, with high (absolute) values of stress triaxiality in the workpiece ahead of the cutting tool, which leads to a general over-prediction 
of cutting forces by the J-C model within our computational framework. The implications of this finding are that the accuracy of cutting simulations involving porous cellular structures relies heavily on choosing correct constitutive material models that account for the complex yield-behaviour of such materials.

While the modelling framework has provided very good predictions of overall cutting behaviour, there are certain limitations within this study that should be acknowledged. While initial post-yield behaviour of the computational model was determined based on uniaxial compression testing, subsequent damage (or softening) behaviour was described by a damage evolution law (Eq. 8), which is formulated as a function of the equivalent plastic strain (PEEQ) at failure. Due to the difficulty in experimentally determining the individual damage parameters $\left(d_{1}-d_{3}\right)$ for this evolution law, our study used an iterative process to calibrate a set of damage constants until an appropriate representation of chip formation compared to the experiments was observed. This process was not trivial as the computational model was required to capture many different categories of chip formation. Considering the complex dynamic failure processes taking place ahead of the tool tip during orthogonal cutting, the calibrated parameters correctly predicted chip formation in all but one of the cases examined. It should be noted that the case where the model failed to capture chip formation $\left(\alpha=20^{\circ}, h=1 \mathrm{~mm}\right)$, several different types of chip formation were observed experimentally (Type $3 a$ and $3 b$ ), suggesting that there may have been a transition in chip formation occurring for these set of parameters. An alternative reason could be the use of a continuum-based modelling approach for the PU foam material. While this study represents the first implementation of a CFI plasticity model for this type of foam structure, this constitutive formulation may have difficulty in capturing certain features occurring at particular length-scales within this cellular solid. It is worth noting that the PU20 foam used is described by the manufacturer as a closed-cell rigid cellular foam. While this material has been shown to have similar bulk post-yield mechanical behaviour as trabecular bone, the characteristic cell size is much smaller $(\sim 0.17 \mathrm{~mm})$ than trabecular bone, whose pore dimensions would be closer to the cutting depths used in this study $(1-2 \mathrm{~mm})$. At this scale, it may be the case that a discrete modelling approach where the cell walls themselves are represented may be required to capture these intricate features of the cutting process.

\section{Conclusions}

In summary, the study presents a systematic experimental-computational investigation of how key cutting parameters govern orthogonal cutting performance. A novel finite element model was developed that combined a CFI plasticity model and a damage evolution law to accurately predict chip formation and cutting forces in high-speed cutting simulations of trabecular bone analogues. This is the first experimentally-validated modelling framework that predicts chip formation and cutting forces in high-speed cutting model of trabecular analogues. The modelling framework developed has excellent potential to be extended to three-dimensional situations, and could be used for the design of cutting tools in more operations such as burring and drilling. 
Author Contributions: Conceptualization, M.O'N and T.V; methodology, M.O'N and T.V; software, M.O'N.; validation, M.O'N; formal analysis, M.O'N; investigation, M.O'N; data curation, $\mathrm{M}, \mathrm{O}^{\prime} \mathrm{N}$.; writing - original draft preparation, $\mathrm{M}, \mathrm{O}^{\prime} \mathrm{N}$..; writing-review and editing, M.O'N and T.V.; supervision, T.V.; project administration, T.V.; funding acquisition, T.V. All authors have read and agreed to the published version of the manuscript.

Funding: This research was funded by a College of Engineering and Informatics Fellowship at the National University of Ireland Galway.

Conflicts of Interest: The authors declare no conflict of interest. 


\section{References}

1. Abdel-Wahab, A.A., K. Alam, and V.V. Silberschmidt, Analysis of anisotropic viscoelastoplastic properties of cortical bone tissues. Journal of the Mechanical Behavior of Biomedical Materials, 2011. 4(5): p. 807-820.

2. Vaughan, T.J., C.T. McCarthy, and L.M. McNamara, A three-scale finite element investigation into the effects of tissue mineralisation and lamellar organisation in human cortical and trabecular bone. J Mech Behav Biomed Mater, $2012.12(0)$ : p. 50-62.

3. Li, S., et al., Penetration of cutting tool into cortical bone: experimental and numerical investigation of anisotropic mechanical behaviour. J Biomech, 2014. 47(5): p. 1117-26.

4. $\quad$ Fox, M.J., et al., Lateral drill holes decrease strength of the femur: an observational study using finite element and experimental analyses. J Orthop Surg Res, 2013. 8: p. 29.

5. Dillon, N.P., et al., An experimental evaluation of the force requirements for robotic mastoidectomy. Otology \& neurotology : official publication of the American Otological Society, American Neurotology Society [and] European Academy of Otology and Neurotology, 2013. 34(7): p. e93-e102.

6. $\quad$ Krause, W.R., Orthogonal bone cutting: saw design and operating characteristics. J Biomech Eng, 1987. 109(3): p. 263-71.

7. Sui, J., et al., FORCE ANALYSIS OF ORTHOGONAL CUTTING OF BOVINE CORTICAL BONE. Machining Science and Technology, 2013. 17(4): p. 637-649.

8. Malak, S.F.F. and I.A. Anderson, Orthogonal cutting of polyurethane foam. International Journal of Mechanical Sciences, 2005. 47(6): p. 867-883.

9. Malak, S.F. and I.A. Anderson, Orthogonal cutting of cancellous bone with application to the harvesting of bone autograft. Med Eng Phys, 2008. 30(6): p. 717-24.

10. Yeager, C., A. Nazari, and D. Arola, MACHINING OF CORTICAL BONE: SURFACE TEXTURE, SURFACE INTEGRITY AND CUTTING FORCES. Machining Science and Technology, 2008. 12(1): p. 100-118.

11. Marco, M., et al., A review on recent advances in numerical modelling of bone cutting. Journal of the Mechanical Behavior of Biomedical Materials, 2015. 44: p. 179-201.

12. Goldstein, S.A., The mechanical properties of trabecular bone: dependence on anatomic location and function. J Biomech, 1987. 20(1112): p. 1055-61.

13. Keaveny, T.M., et al., Trabecular bone modulus and strength can depend on specimen geometry. J Biomech, 1993. 26(8): p. 991-1000.

14. Morgan, E.F., H.H. Bayraktar, and T.M. Keaveny, Trabecular bone modulus-density relationships depend on anatomic site. J Biomech, 2003. 36(7): p. 897-904.

15. Cseke, A. and R. Heinemann, The effects of cutting parameters on cutting forces and heat generation when drilling animal bone and biomechanical test materials. Medical Engineering \& Physics, 2018. 51: p. 24-30.

16. Kusins, J.R., O.R. Tutunea-Fatan, and L.M. Ferreira, Experimental analysis of the process parameters affecting bone burring operations. Proc Inst Mech Eng H, 2018. 232(1): p. 33-44.

17. Umbrello, D., R. M'Saoubi, and J.C. Outeiro, The influence of Johnson-Cook material constants on finite element simulation of machining of AISI 316L steel. International Journal of Machine Tools and Manufacture, 2007. 47(3): p. 462-470.

18. Mamalis, A.G., et al., Finite element simulation of chip formation in orthogonal metal cutting. Journal of Materials Processing Technology, 2001. 110(1): p. 19-27.

19. Rhim, S.-H. and S.-I. Oh, Prediction of serrated chip formation in metal cutting process with new flow stress model for AISI 1045 steel. Journal of Materials Processing Technology, 2006. 171(3): p. 417-422.

20. Özel, T. and Y. Karpat, Identification of Constitutive Material Model Parameters for High-Strain Rate Metal Cutting Conditions Using Evolutionary Computational Algorithms. Materials and Manufacturing Processes, 2007. 22(5): p. 659-667.

21. Johnson, G.R. and W.H. Cook, Fracture characteristics of three metals subjected to various strains, strain rates, temperatures and pressures. Engineering Fracture Mechanics, 1985. 21(1): p. 31-48.

483 
22. Alam, K., A.V. Mitrofanov, and V.V. Silberschmidt, Finite element analysis of forces of plane cutting of cortical bone. Computational Materials Science, 2009. 46(3): p. 738-743.

23. Tu, Y.-K., et al., Finite Element Simulations of Bone Temperature Rise During Bone Drilling Based on a Bone Analog. Journal of Medical and Biological Engineering, 2013. 33: p. 269-274.

24. Santiuste, C., et al., The influence of anisotropy in numerical modeling of orthogonal cutting of cortical bone. Composite Structures, 2014. 116: p. 423-431.

25. Sezek, S., B. Aksakal, and F. Karaca, Influence of drill parameters on bone temperature and necrosis: A FEM modelling and in vitro experiments. Computational Materials Science, 2012. 60: p. 13-18.

26. Childs, T.H.C. and D. Arola, MACHINING OF CORTICAL BONE: SIMULATIONS OF CHIP FORMATION MECHANICS USING METAL MACHINING MODELS. Machining Science and Technology, 2011. 15(2): p. 206-230.

27. Kelly, N. and J.P. McGarry, Experimental and numerical characterisation of the elasto-plastic properties of bovine trabecular bone and a trabecular bone analogue. J Mech Behav Biomed Mater, 2012. 9: p. 184-97.

28. Kelly, N., et al., An investigation of the inelastic behaviour of trabecular bone during the press-fit implantation of a tibial component in total knee arthroplasty. Medical Engineering \& Physics, 2013. 35(11): p. 1599-1606.

29. Davim, J.P. and N. Marques, Dynamical experimental study of friction and wear behaviour of bovine cancellous bone sliding against a metallic counterface in a water lubricated environment. Journal of Materials Processing Technology, 2004. 152(3): p. 389-394.

30. Deshpande, V.S. and N.A. Fleck, Isotropic constitutive models for metallic foams. Journal of the Mechanics and Physics of Solids, 2000. 48(6): p. 1253-1283.

31. Shaw, M.C., Metal Cutting Principles. 1986, New York: Oxford University Press. 